[Berliner Entomolog. Zeitschrift Bd. XXXIII. 1889. Heft II.] 401

\title{
Ein neuer, dem Weinbau schädlicher Käfer in Tunesien.
}

Mitgetheilt von M. Quedenfeldt.

Wenn auch die seit einigen Jahren in Tunesien recht verheissungsvoll aufblühende Weinkultur bisher von der Phylloxera verschont geblieben ist, so scheint es doch an kleineren Feinden derselben dort nicht ganz zu fehlen. Herr F. An ce y hat im vorigen Jahre in der Chronique agricole der Zeitung "La Tunisie" die Beschreibung eines neuen Käfers aus der Familie der Lamellicornier, Rhizotrogus Cretei, veröffentlicht, über dessen schädliche Thätigkeit bereits Herr Chastine bei seiner im Auftrage des französischen Ministeriums für Landwirthschaft unternommenen Inspizirung der tunesischen Weinberge Kenntniss erhalten und darüber berichtet hatte. Der Käfer ist im Frühjahr 1888 in der Ebene von Mornak, bei Ain-el-Gùsa, nur einige Stunden von Tunis beobachtet worden und zwar zuerst von einem Weinbergbesitzer, Herrn Crété, dessen im Sande und in der leichteren Erde angelegte junge Weinpflanzungen er zum grossen Theile zerstört hatte.

Der Käfer gehört zu der von Guérin Ménéville für eine, meist dem nordwestlichen Afrika angehörige Rhizotrogen-Gruppe gegründeten Untergattung Geotrogus. Der Mehrzahl nach sind dies ungeflügelte Spezies, die in der Frde und unter Steinen u. s. w. leben. Die Weibchen leben fast ausschliesslich subterran, sind daher auch viel seltener als die Männchen, welche letzteren, meist gegen Abend und Nachts, an den jungen Schösslingen verschiedener Pflanzen emporklimmen und dieselben benagen.

Von mehreren in Algerien einheimischen Arten dieser Untergattung ist bereits ihre Schädlichkeit für den Weinbau konstatirt. Im Larvenzustande greifen sie die jungen Wurzeln, als vollendetes Insekt die zarten Schösslinge der Weinpflanze an.

Die in Rede stehende Spezies ist, wie gesagt, neu, und man kennt bis jetzt nur die Männchen. Die Beschreibung ist folgende:

XXXIII. Heft II. 
402 M. Quedenfeldt: ein neuer, dem Weinbau schädlich. Käfer etc.

Rhizotrogus (Geotrogus) Cretei Ancey. Long. 8-9 mill. Lat. 4-5 mill. Mas apterus, brunneus, punctulatus ac nitidus, haud flavus ad prothoracis latera, his sinuatis et angulatis ad basin. Elytris medio inflatis, basi angustioribus et apice truncatis, regulariter incurvatis ad humeros sine longitudinale carina. Pygidium laeviter punctulatum. Femina ignota. - Patria Tunisia.

Geotrogus Cretei ist die kleinste bis jetzt bekannte Art dieser Gruppe und steht dem sinuatocollis Fairm. und gabalus Buquet nahe. Er unterscheidet sich von diesen durch die folgenden Hauptmerkmale: 1) Konstant geringere Grösse. 2) Durch das Fehlen des gelben Randes des Prothorax. 3) Durch das Fehlen einer Mittellinie auf dem konvex geformten und gleichmässig punktirten Prothorax.

Ohne Zweifel wird es bald gelingen, auch der Weibchen, sowie der Larven habhaft zu werden. In Algerien hat man in ähnlichen Fällen durch Einsammeln des entwickelten Insekts in grossen Quantitäten bei Nacht dasselbe zu vertilgen gesucht - ein Mittel, welches jedoch nie einen radikalen Erfolg haben kann. 


\section{$2 \mathrm{BHL}$ Biodiversity Heritage Library}

Quedenfeldt, Max. 1889. "Ein neuer, dem Weinbau schädlicher Käfer in Tunesien." Berliner entomologische Zeitschrift / herausgegeben von dem Entomologischen Verein in Berlin 33, 401-402. https://doi.org/10.1002/mmnd.18900330224.

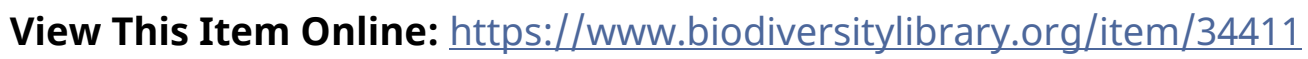

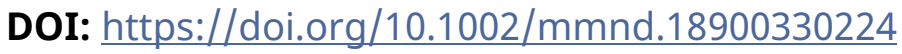

Permalink: https://www.biodiversitylibrary.org/partpdf/20632

\section{Holding Institution}

Smithsonian Libraries

\section{Sponsored by}

Smithsonian

\section{Copyright \& Reuse}

Copyright Status: NOT_IN_COPYRIGHT

This document was created from content at the Biodiversity Heritage Library, the world's largest open access digital library for biodiversity literature and archives. Visit BHL at https://www.biodiversitylibrary.org. 